\title{
REPETITIVE PAROXYSMAL VENTRICULAR TACHYCARDIA WITH FUSION BEATS
}

\author{
BY \\ RUSTOM JAL VAKIL \\ From the Cardiological Department, King Edward Memorial Hospital, Bombay
}

Paroxysmal ventricular tachycardia is unfortunately fairly common and is usually associated with serious heart disease and a poor prognosis. Of late, however, attention has been drawn by numerous observers to a rare and apparently benign form where paroxysms of ventricular tachycardia interrupted by normal sinus beats keep on recurring for months or years.

In view of the apparent rarity of the repetitive form of paroxysmal ventricular tachycardia and the presence of some unusual features the following case is reported.

\section{Case Record}

A Hindoo shopkeeper, aged 38 years, was investigated for vague attacks of palpitation accompanied by sweating. Until the age of 36 , he had always been well, and had indulged in strenuous physical exercise. In early 1954, for no apparent reason he started having momentary attacks of irregular or fast beating of the heart accompanied by sweating but no pain or dyspnœa. These attacks were extremely variable in intensity, duration, and frequency, sometimes occurring as often as " several hundred times a day," sometimes only once or twice in the day. They seemed more frequent after physical effort. In spite of and even during the attacks, he had continued working at his job and indulged in moderate exertion.

On examination, he was a thin man of average height and good colour. Apart from irregular beating of the heart, the cardiovascular system was normal, both clinically and fluoroscopically; the blood pressure was 120/84. The Wassermann and Kahn reactions were negative and the blood count and urine and the other systems were normal.

Electrocardiograms (Fig. 1) taken on several occasions revealed characteristic paroxysms of ventricular tachycardia of variable length interrupted by one or more normal sinus beats. They were sometimes preceded by ventricular fusion beats (marked $F$ in the Fig.) and were followed by long pauses.

With the oral administration of quinidine sulphate, $0 \cdot 2 \mathrm{~g}$. four times daily for twelve days, the paroxysms were controlled and the patient became free of all symptoms. Throughout the entire period of illness, he had not become incapacitated.

\section{Discussion}

The repetitive form of paroxysmal ventricular tachycardia, although variously referred to in the past (Gallavardin, 1922; Gallavardin and Dumas, 1924; Cassidy, 1924; and Froment, 1932), is perhaps best described by the term repetitive paroxysmal tachycardia recommended by Parkinson and Papp (1947).

The first case of repetitive paroxysmal tachycardia of auricular type was reported by Lewis in 1909 when, with the aid of the polygraph, he recorded 54 paroxysms of auricular tachycardia within 109 minutes in a healthy man. The ventricular variety was reported independently, for the first time by Gallavardin in France and by Scott in England in 1922. Since then, over thirty cases of this type have been reported by numerous observers, and the subject has been reviewed by Parkinson and Papp (1947).

The favourable outlook of repetitive paroxysmal tachycardia has been the subject of comment (Routier, 1937; Campbell and Elliott, 1939; Miller and Perelman, 1945; and Parkinson and Papp, 
1947). One of the striking features of the present case was the amazing tolerance displayed by the patient towards the disability even while experiencing several hundred paroxysms of tachycardia a day.

The characteristic feature was runs of paroxysms of bizarre ventricular complexes separated by one or more normal sinus beats (Fig. 1). The possibility of supraventricular tachycardia with

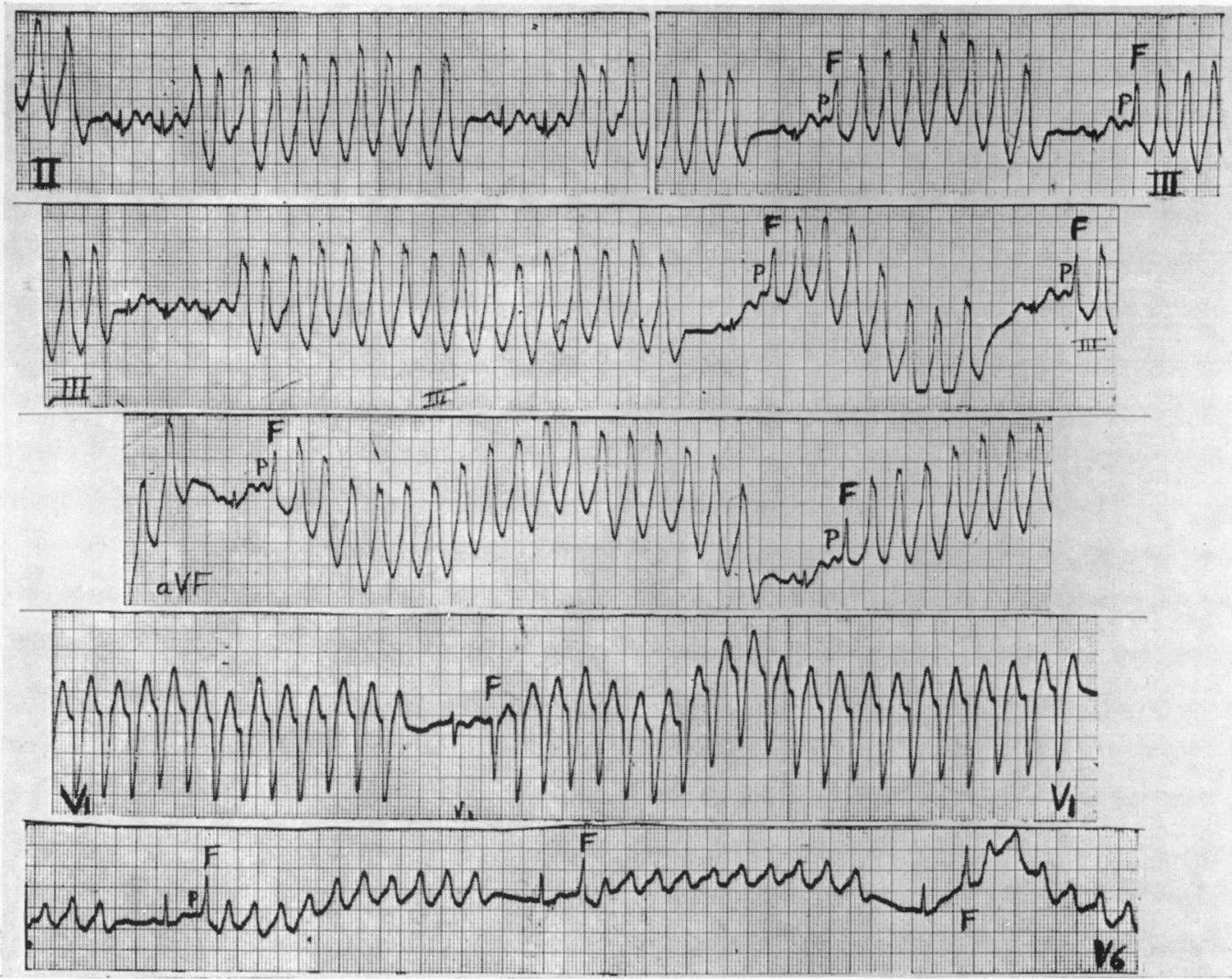

Fig. 1.-Runs of repetitive ventricular paroxysmal tachycardia, interrupted by normal sinus beats. Fusion beats (F) were noted at the onset of some of the paroxysms. The ectopic ventricular beats with bizarre complexes show variations of contour and spacing, the rate ranging between 264 and 214 a minute. The termination of each paroxysm is followed by a characteristic pause. Sinus $P$ waves are difficult to detect during the paroxysms.

aberrant conduction within the ventricles, which has been shown to mimic genuine ventricular tachycardia (Lewis and Master, 1925-26; Gouaux and Ashman, 1947; and Katz and Pick, 1956) was considered in the present case but rejected in view of (1) the variability in the rate of ventricular beating (from 264 to 214 a minute) during paroxysms, (2) the long pause subsequent to each paroxysm, and (3) the somewhat characteristic configuration of the QRST complexes. The condition was therefore regarded as one of paroxysmal ventricular tachycardia of repetitive type.

Another feature of interest was the atypical complex marked $\mathrm{F}$ in Fig. 1. Although most paroxysms of tachycardia were preceded by normal sinus beats, an atypical complex marked $\mathbf{F}$ was found to precede the initial beat of the paroxysm in a fair proportion. In view of the upright $\mathbf{P}$ wave, shortened P-R interval, and QRS configuration intermediate between that of the normal sinus beat and of the bizarre complex of the paroxysm, the $\mathrm{F}$ beat was regarded as an example of a fusion beat (Malinow and Langendorf, 1948) resulting from the fusion of a supraventricular with a ventricular impulse. As far as can be ascertained, this is probably the first case of its kind where 
a fusion beat has been reported in conjunction with repetitive paroxysmal ventricular tachycardia associated with normal sinus rhythm.

\section{Summary}

Repetitive paroxysmal tachycardia of ventricular type is reported in a man of 38 years. Amongst the noteworthy features about the case were (1) the tolerance of the patient towards the disability, and (2) the presence of fusion beats of ventricular type at the onset of many of the paroxysms.

\section{References}

Campbell, M., and Elliott, G. A. (1939). Brit. Heart J., 1, 123.

Cassidy, M. (1924-5). Proc. roy. Soc. Med., Clin. Sect., 18, 14.

Froment, R. (1932). Les Tachycardies Paroxystiques Ventriculaires. Paris.

Gallavardin, L. (1922). Arch. Mal. Cour, 15, 1, 298, 774.

- and Dumas, A. (1924). Arch. Mal. Cour, 17, 87.

Gouaux, J., and Ashman, R. (1947). Amer. Heart J., 34, 366.

Katz, L. N., and Pick, A. (1956). Clinical Electrocardiography. Part I. Philadelphia.

Lewis, T. (1909-10). Heart, 1, 262.

, and Master, A. M. (1925-6), Heart, 12, 209.

Malinow, M. R., and Langendorf, R. (1948). Amer. Heart J., 35, 448.

Miller, R., and Perelman, J. S. (1945). Amer. Heart J., 29, 555.

Parkinson, J., and Papp, C. (1947). Brit. Heart J., 9, 241.

Routier, D. (1937). Arch. Mal. Ceur, 30, 224.

Scott, R. W. (1921-2). Heart, 9, 297. 